\title{
Desempenho produtivo de Brycon orthotaenia em tanques-rede sob diferentes densidades de estocagem
}

\author{
Productive performance of Brycon orthotaenia in cages in different stocking densities
}

\author{
Bruno Olivetti de Mattos $^{\mathrm{I}^{*}}$ Adriano Carvalho Costa ${ }^{\mathrm{I}}$ Renato Silva Leal $^{\mathrm{II}}$ \\ Rilke Tadeu Fonseca de Freitas ${ }^{\mathrm{I}}$ Maria Emília de Sousa Gomes Pimenta ${ }^{\text {II }}$ \\ Thiago Archangelo Freato ${ }^{\text {III }}$
}

\section{RESUMO}

O objetivo deste trabalho foi determinar a densidade de estocagem de matrinxã (Brycon orthotaenia) em tanques-rede, considerando o desempenho produtivo. Foram utilizados 5.280 juvenis de Brycon orthotaenia com peso inicial de $115,2 g \pm 5,7$ os quais foram distribuidos em 16 tanques-rede de $4 \mathrm{~m}^{3}$ nas densidades de 45, 70, 95 e 120 peixes $m^{-3}$ em quatro repetições. Os peixes foram alimentados com ração comercial de $40 \%$ de proteina bruta durante o periodo experimental. Os dados foram submetidos à análise de variância e à regressão linear para estimativa do melhor ajuste a $5 \%$ de probabilidade. Os parâmetros produtivos como sobrevivência, peso inicial, peso final, conversão alimentar e taxa de crescimento específico não foram influenciados pela densidade de estocagem, assim como os parâmetros de qualidade da água. Entretanto, para a variável biomassa final, ganho de biomassa e consumo de ração total, o efeito foi significativo e estas apresentaram relação linear positiva com a densidade de estocagem. Avaliando os resultados, pode-se concluir que a densidade de estocagem de matrinxã (Brycon orthotaenia) até 120 peixes $m^{-3}$ é a que proporciona maior produtividade e não representa efeitos negativos sobre o desempenho dos peixes.

Palavras-chave: aquicultura, sistema intensivo, rio São Francisco.

\section{ABSTRACT}

The objective of this study was to determine the stocking density of matrinxã (Brycon orthotaenia) in cages, considering the productive performance. Juvenile Brycon orthotaenia $(n=5280)$ were distributed in 16 cages of $4 m^{3}$ at densities of 45, 70, 95 and 120 fish $\mathrm{m}^{-3}$. The fish were fed with commercial feed with $40 \%$ crude protein during all experimental period. Data were subjected to analysis of variance and linear regression to estimate the best fit using 5\% probability. The production parameters such as survival, initial weight, final weight, feed conversion and specific growth rate were not influenced by stocking density, as well as the parameters of water quality. However, final biomass, biomass gain and feed intake showed a positive linear relationship with stocking density. Evaluating these results, it was concluded that the stocking density of matrinxã (Brycon orthotaenia) up to 120 fish $\mathrm{m}^{-3}$ represent the best productive performance.

Key words: aquaculture, intensive system, São Francisco river.

\section{INTRODUÇÃO}

A Bacia Hidrográfica do São Francisco que drena áreas dos Estados de Minas Gerais, Bahia, Pernambuco, Alagoas, Sergipe e o Distrito Federal passa por três biomas (cerrado, caatinga e mata atlântica) (WELCOMME, 1985), perfazendo uma área total inundada de $5.856,2 \mathrm{~km}^{2}$ (IBGE, 1999), a qual é dividida em quatro segmentos: alto, médio, submédio e baixo (PAIVA, 1982). As principais atividades desenvolvidas ao longo da Bacia Hidrográfica do São Francisco é a produção de energia elétrica, a irrigação, a pesca esportiva e profissional, o abastecimento urbano e rural, a navegação, a mineração e a aquicultura (VALENCIO et al., 2003).

A ictiofauna da Bacia compreende cerca de 160 espécies de peixes de água doce (SATO \& GODINHO, 1999). Entretanto, os impactos gerados por meio das construções de barragens,

IDepartamento de Zootecnia, Universidade Federal de Lavras (UFLA), Campus Universitário, CP 3037, 37200-000, Lavras, MG, Brasil.

E-mail: mattos.bo@gmail.com.*Autor para correspondência.

IIDepartamento de Ciência dos Alimentos, UFLA, Campus Universitário, Lavras, MG, Brasil.

IIIDepartamento de Piscicultura, Empresa de Pesquisa Agropecuária de Minas Gerais (EPAMIG), Leopoldina, MG, Brasil. 
desmatamento das margens, emissão de efluentes industriais e domésticos no corpo hídrico sem tratamento, destruição das lagoas marginais, pesca predatória e introdução de espécies exóticas fazem com que os habitats dos peixes, a rota de migração, as fontes de alimentos e os locais de reprodução sejam alterados (ZANIBONI FILHO, 2005) e, consequentemente, ocorra uma diminuição dos estoques pesqueiros. Esses fatores afetam a ictiofauna da Bacia do São Francisco e ameaça de extinção algumas espécies como a matrinxã (Brycon orthotaenia), curimatá (Prochilodus vimboides) e dourado (Salminus brasiliensis) (IUCN, 2011), que são importantes econômica e ecologicamente nessa região (SATO et al., 2003). Dessa forma, há a necessidade de serem criados mecanismos de preservação e desenvolvimento de novas técnicas para seu cultivo.

Dentre as espécies nativas em risco ambiental, está a matrinxã, que é bastante apreciada em diversos Estados Brasileiros, pois é uma espécie que se desenvolve com índices satisfatórios de crescimento, peso e conversão alimentar em sistemas de cultivo e apresenta bons níveis de qualidade de carne (IZEL et al., 2005). Estudos sobre o cultivo da matrinxã do São Francisco em tanques-rede são escassos, principalmente no que se refere à melhor densidade de estocagem para essa espécie na fase inicial de engorda. Segundo BRANDÃO et al. (2004), a determinação dessa densidade é importante, pois o sucesso da criação se dá pelo bom desempenho nessa fase.

Segundo SURESH \& LIN (1992), a densidade de estocagem tem efeito significativo sobre a taxa de crescimento e taxa de conversão alimentar. Segundo SOUZA (1996), essa influência sobre o crescimento dos peixes se deve, sobretudo, em função da competição por espaço, alimentos e oxigênio. Assim, este trabalho foi realizado com o objetivo de determinar a densidade de estocagem de matrinxã (Brycon orthotaenia) em tanques-rede, considerando o desempenho produtivo.

\section{MATERIAL E MÉTODOS}

O experimento foi conduzido em um braço do Reservatório da usina hidroelétrica de Três Marias, dentro do Centro de Pesquisa, Demonstração e Treinamento de Cultivo de Peixes em Tanques-rede da Fazenda Experimental da Empresa de Pesquisa Agropecuária de Minas Gerais (EPAMIG), em Felixlândia-MG. O município de Felixlândia/MG localiza-se na região central do estado, a uma altitude média de 731 metros, tendo como coordenadas geográficas 18\%43'51'"de latitude sul e 4453'33" longitude oeste de Greenwich (BRASIL, 1992) e temperatura média anual de $22,6^{\circ} \mathrm{C}$, máxima de $30,2^{\circ} \mathrm{C}$ e mínima de $16,6^{\circ} \mathrm{C}$.

Foram utilizados neste experimento 5.280 juvenis de Brycon orthotaenia, com peso médio de $115,22 \pm 7,71 \mathrm{~g}$ e $16,74 \pm 0,42 \mathrm{~cm}$ de comprimento, distribuídos em 16 tanques-rede de $4 \mathrm{~m}^{3}$ e malha de $20 \mathrm{~mm}$ entrenós. Após a estocagem, os peixes passaram por um período pré-experimental de 10 dias, já nas densidades a serem testadas, para adaptação às novas condições de cultivo.

$\mathrm{O}$ experimento foi realizado em delineamento inteiramente casualizado, com quatro tratamentos e quatro repetições, sendo o tanque-rede a unidade experimental. Os tratamentos consistiram de quatro diferentes densidades de estocagem 45, 70, 95 e 120 juvenis $\mathrm{m}^{-3}$.

Os peixes foram alimentados até a saciedade aparente, três vezes ao dia, com ração comercial extrusada de 2 a $4 \mathrm{~mm}$, contendo $40 \%$ de proteína bruta, conforme recomendação do fabricante, e a quantidade de ração fornecida diariamente foi registrada para o cálculo do consumo de ração.

No início do experimento e aos 30, 60, 90 dias de cultivo, após jejum de 24 horas, uma amostra aleatória de $10 \%$ dos peixes de cada tanque-rede foi retirada, sendo os peixes amostrados anestesiados com 50 $\mathrm{mg} \mathrm{L}^{-1}$ de óleo de cravo (INOUE et al., 2003), pesados e medidos para o ajuste da taxa de arraçoamento e para posterior avaliação do crescimento ponderal. Em seguida, foram devolvidos aos tanques-rede de origem.

Ao final do experimento, foi realizada a despesca total de cada unidade experimental, sendo todos os peixes coletados insensibilizados por meio da secção da medula e sangria por corte das brânquias, conforme PEDRAZANI (2007). Também foi realizada a avaliação de alguns parâmetros de qualidade de água dentro dos tanques-rede durante o período experimental, como temperatura máxima e mínima, oxigênio dissolvido, $\mathrm{pH}$, amônia, nitrito e nitrato.

Com os dados obtidos, foram avaliados os seguintes parâmetros produtivos: taxa de sobrevivência (\%), peso final (g), biomassa final $(\mathrm{kg})$, ganho de biomassa $(\mathrm{kg})$, consumo de ração total $(\mathrm{kg})$, conversão alimentar aparente [consumo de ração total/ganho de biomassa total], coeficiente de variação do comprimento padrão $[\mathrm{CVCP}=($ desvio padrão do comprimento / comprimento médio) $\mathrm{X}$ $100]$, coeficiente de variação do peso [CVP $=($ desvio padrão do peso / peso médio) $x$ 100] e a taxa de 
crescimento específico $(\% /$ dia $)[\mathrm{TCE}=((\ln$ peso final ln peso inicial / dias de cultivo) x 100].

Os dados obtidos foram submetidos ao teste de Lilliefors, para verificação da normalidade dos dados. Posteriormente, os dados foram submetidos à análise de variância e regressão linear, para determinação da densidade de estocagem, optando-se pela equação de melhor ajuste aos dados.

Para a realização das análises estatísticas, foi utilizado o pacote computacional SAEG Sistema para Análises Estatísticas, versão 9.0 (Universidade Federal de Viçosa), sendo a análise de variância realizada de acordo com o seguinte modelo estatístico: $Y_{\mathrm{ij}}=\mu+D_{\mathrm{i}}+\mathrm{e}_{\mathrm{ij}}$. Em que: $\mathrm{Y}_{\mathrm{ij}}$ : - observação $\mathrm{j}$ realizada na densidade $i ; \mu$ - média geral de $Y ; D_{i}-$ efeito da densidade de estocagem $i, i=1,2,3$ e 4 ; $e_{i j}-$ erro associado a cada observação, NID $\sim(\mu, \sigma)$.

\section{RESULTADOS E DISCUSSÃO}

Os valores médios dos parâmetros de qualidade de água, avaliados durante o cultivo, permaneceram nos limites preconizados pela Resolução n.357 de 2005, do Conselho Nacional do Meio Ambiente (CONAMA) para água doce, classificada em classe II, em uso na aquicultura, os quais não foram influenciados pela densidade de estocagem (Tabela 1).

As variáveis de sobrevivência, peso final, conversão alimentar aparente e taxa de crescimento específico não foram influenciadas $(\mathrm{P}>0,05)$ pela densidade de estocagem. Entretanto, observou-se um efeito linear positivo $(\mathrm{P}<0,01)$ sobre as variáveis de biomassa final, ganho de biomassa e consumo de ração, que aumentaram proporcionalmente com a densidade de estocagem (Tabela 2).
Como pode ser observado na figura 1 , a biomassa final, ganho de biomassa e consumo de ração total obtiveram o ápice na maior densidade de estocagem (120 peixes $\mathrm{m}^{-3}$ ).

PEDREIRA et al. (2010) obtiveram resultados semelhantes estudando Brycon orthotaenia em tanques-rede, na fase inicial de cultivo $(90,00 \mathrm{~g} \pm 0,15)$, em diferentes densidades de estocagem $\left(20,40\right.$ e 60 peixes $\left.\mathrm{m}^{-3}\right)$, quando, com o aumento da densidade, ocorreu maior ganho de biomassa, maior biomassa do tanque e de consumo de ração. Resultados de outros autores corroboram o resultado encontrado neste estudo. BRANDÃO et al. (2005), em seu trabalho com Brycon amazonicus na fase de recria em tanques-rede, observaram que a biomassa final, o ganho de biomassa e o consumo de ração durante todo o experimento foi maior com o aumento da densidade $(200,300,400$ e 500 peixes $\mathrm{m}^{-3}$ ). LAGO (2010), estudando a fase de recria de Brycon orthotaenia $(0,74$ a $67 \mathrm{~g})$ em diferentes densidades de estocagem com 150, 300, 450 e 600 peixes $\mathrm{m}^{-3}$, observou esse mesmo comportamento.

O consumo de ração e a densidade de estocagem não afetaram o peso final dos peixes, assim como nos trabalhos de BRANDÃO et al. (2005), LAGO (2010) e CARVALHO et al. (1997) que obtiveram resultados semelhantes com Brycon amazonicus, Brycon orthotaenia e Brycon cephalus, respectivamente. Ao contrário desses estudos, alguns autores têm observado que o peso final de diferentes espécies de peixes pode ser influenciado pela densidade de estocagem, como PIAIA \& BALDISSEROTTO (2000) que, avaliando a densidade de estocagem de alevinos de Rhamdia quelen, observaram aumento do peso final nas densidades de estocagem mais elevadas. Já os autores VILELA \& HAYASHI (2001)

Tabela 1 - Valores médios dos parâmetros de qualidade de água durante o período experimental com matrinxã (Brycon orthotaenia) em tanques-rede.

\begin{tabular}{|c|c|c|c|c|c|}
\hline \multirow{2}{*}{ Parâmetros de Qualidade de Água } & \multicolumn{5}{|c|}{ - } \\
\hline & 45 & 70 & 95 & 120 & Conama $357 *$ \\
\hline Temperatura Máxima $\left({ }^{\circ} \mathrm{C}\right)$ & $24,22 \pm 0,16$ & $24,21 \pm 0,14$ & $24,25 \pm 0,17$ & $24,20 \pm 0,18$ & --- \\
\hline Temperatura Mínima $\left({ }^{\circ} \mathrm{C}\right)$ & $22,58 \pm 0,13$ & $22,50 \pm 0,18$ & $22,55 \pm 0,15$ & $22,53 \pm 0,16$ & --- \\
\hline Oxigênio Dissolvido (mg L $\left.{ }^{-1}\right)$ & $6,22 \pm 0,12$ & $6,26 \pm 0,18$ & $6,27 \pm 0,13$ & $6,31 \pm 0,12$ & $\geq 5$ \\
\hline $\mathrm{pH}$ & $6,40 \pm 0,11$ & $6,40 \pm 0,11$ & $6,40 \pm 0,11$ & $6,40 \pm 0,11$ & 6 a 9 \\
\hline Amônia $\left(\mathrm{mg} \mathrm{L}^{-1}\right)$ & $0,04 \pm 0,01$ & $0,03 \pm 0,07$ & $0,03 \pm 0,01$ & $0,04 \pm 0,01$ & $\leq 0,05$ \\
\hline Nitrito $\quad\left(\mathrm{mg} \mathrm{L}^{-1}\right)$ & $0,003 \pm 0,000$ & $0,003 \pm 0,000$ & $0,003 \pm 0,000$ & $0,003 \pm 0,000$ & $\leq 1$ \\
\hline Nitrato $\quad\left(\mathrm{mg} \mathrm{L}^{-1}\right)$ & $0,28 \pm 0,04$ & $0,33 \pm 0,059$ & $0,29 \pm 0,04$ & $0,28 \pm 0,04$ & $\leq 10$ \\
\hline
\end{tabular}

* Resolução n.357, de 17 de março de 2005 - Dispõe sobre a classificação dos corpos de água e diretrizes ambientais para o seu enquadramento, bem como estabelece as condições e padrões de lançamento de efluentes, e dá outras providências.

Ciência Rural, v.43, n.6, jun, 2013. 
Tabela 2 - Valores médios dos parâmetros produtivos encontrados durante o período experimental com matrinxã (Brycon orthotaenia) em tanques-rede.

\begin{tabular}{|c|c|c|c|c|c|}
\hline \multirow{2}{*}{ Variáveis } & \multirow[b]{2}{*}{45} & \multirow[b]{2}{*}{70} & \multirow[b]{2}{*}{95} & \multirow[b]{2}{*}{120} & \multirow[b]{2}{*}{$\mathrm{CV}(\%)$} \\
\hline & & & & & \\
\hline Sobrevivência (\%) & 99,31 & 91,07 & 90,72 & 96,56 & 6,15 \\
\hline Peso Inicial (g) & 112,68 & 116,88 & 109,15 & 122,23 & 5,65 \\
\hline Peso Final (g) & 238,23 & 234,79 & 241,26 & 239,43 & 7,83 \\
\hline Conversão Alimentar Aparente & 1,25 & 1,46 & 1,29 & 1,25 & 10,81 \\
\hline Taxa de Crescimento Específico $\left(\% \mathrm{dia}^{-1}\right)$ & 0,70 & 0,65 & 0,74 & 0,62 & 17,82 \\
\hline${ }^{(1)}$ Biomassa Final (kg) & 42,61 & 60,00 & 83,03 & 110,87 & 10,23 \\
\hline${ }^{(1)}$ Ganho de Biomassa (kg) & 22,33 & 27,27 & 41,56 & 52,20 & 25,25 \\
\hline${ }^{(1)}$ Consumo de Ração Total (kg) & 27,45 & 38,90 & 52,44 & 64,55 & 17,30 \\
\hline
\end{tabular}

(1) Efeito Linear $(\mathrm{P}<0,01)$.

obtiveram como resultado do cultivo de juvenis de Astyanax bimaculatus, em diferentes densidades, um efeito linear negativo, ou seja, o peso final foi inversamente proporcional à densidade, assim como PEDREIRA et al. (2010), estudando o efeito da densidade de estocagem sobre o peso final em juvenis de Brycon orthotaenia. Com base nos resultados encontrados para as diversas espécies e para o estudo em questão, pode-se afirmar que o efeito da densidade de estocagem sobre o peso final do peixe pode estar diretamente relacionado com a idade, tamanho, espécie, manejo e época do ano.

A taxa de sobrevivência apresentou níveis elevados e não houve diferença significativa. TURRA et al. (2009), estudando juvenis de Pseudoplatystoma $\boldsymbol{s p}$., também observaram altas taxas de sobrevivência (95,97; 97,80 e 96,73\%) sem influência da densidade de estocagem. MARQUES et al. (2004), utilizando sistema intensivo para estudar alevinos de Brycon cephalus, em diferentes densidades de estocagem, obtiveram baixa taxa de sobrevivência $(66,67$; 43,$33 ; 41,67$ e $48,33 \%$ ), que não foi afetada pela densidade e sim pelo canibalismo dos peixes, o que pôde ser confirmado com os ferimentos dos peixes. LAGO (2010), estudando a fase de recria de Brycon orthotaenia, observou uma baixa taxa de sobrevivência $(88,10 ; 68,80 ; 48,70$ e $39,10 \%)$, devido ao canibalismo, entretanto, com efeito linear negativo da densidade de estocagem. A sobrevivência dos peixes no sistema de cultivo pode ser afetada diretamente pela densidade de estocagem, devido à redução do espaço, prejudicando a alimentação $\mathrm{e}$ locomoção, ou por outros fatores, como, por exemplo, o comportamento agressivo de algumas espécies, que acarreta em canibalismo.
A conversão alimentar não foi influenciada pelo aumento das densidades, sendo os valores encontrados próximos ao de alguns trabalhos realizados com peixes do mesmo gênero. MARQUES et al. (2004) obtiveram, através do estudo com alevinos de Brycon cephalus (2 a 30 gramas), em sistema intensivo de produção, uma conversão média de 1,29. Porém, BRANDÃO et al. (2005), em trabalho com Brycon amazonicus sob diferentes densidades de estocagem na fase de recria $(200,300,400$ e 500 peixes $\mathrm{m}^{-3}$ ), relataram uma conversão média de 1,32 , o que está muito próximo do encontrado do presente estudo, que apresentou conversão média de 1,31. Todavia, TORTOLERO et al. (2010) observaram uma influência da densidade sobre a conversão alimentar, quando os alevinos de Brycon amazonicus foram cultivados em diferentes densidades de estocagem $\left(100,150,200\right.$ e 250 peixes $\left.\mathrm{m}^{-3}\right)$, assim como LAGO (2010), que observou efeito linear positivo na fase de recria de Brycon orthotaenia, devido à alta mortalidade dos peixes.

A taxa de crescimento específico não apresentou diferença significativa em relação à densidade de estocagem, denotando que, no período de cultivo, a taxa de estocagem não proporcionou efeito sobre o espaço disponível do tanque-rede. BRANDÃO et al. (2005) e GOMES et al. (2004), avaliando Colossoma macropomum na fase de recria, também não observaram influência da densidade sobre a taxa de crescimento específico. FRASCASCORVO et al. (2007), trabalhando com Brycon amazonicus, encontraram valores próximos ao desse estudo. Porém, PIAIA \& BALDISSEROTTO (2000), trabalhando com alevinos de Rhamdia quelen em diferentes densidades, relataram efeito linear positivo 


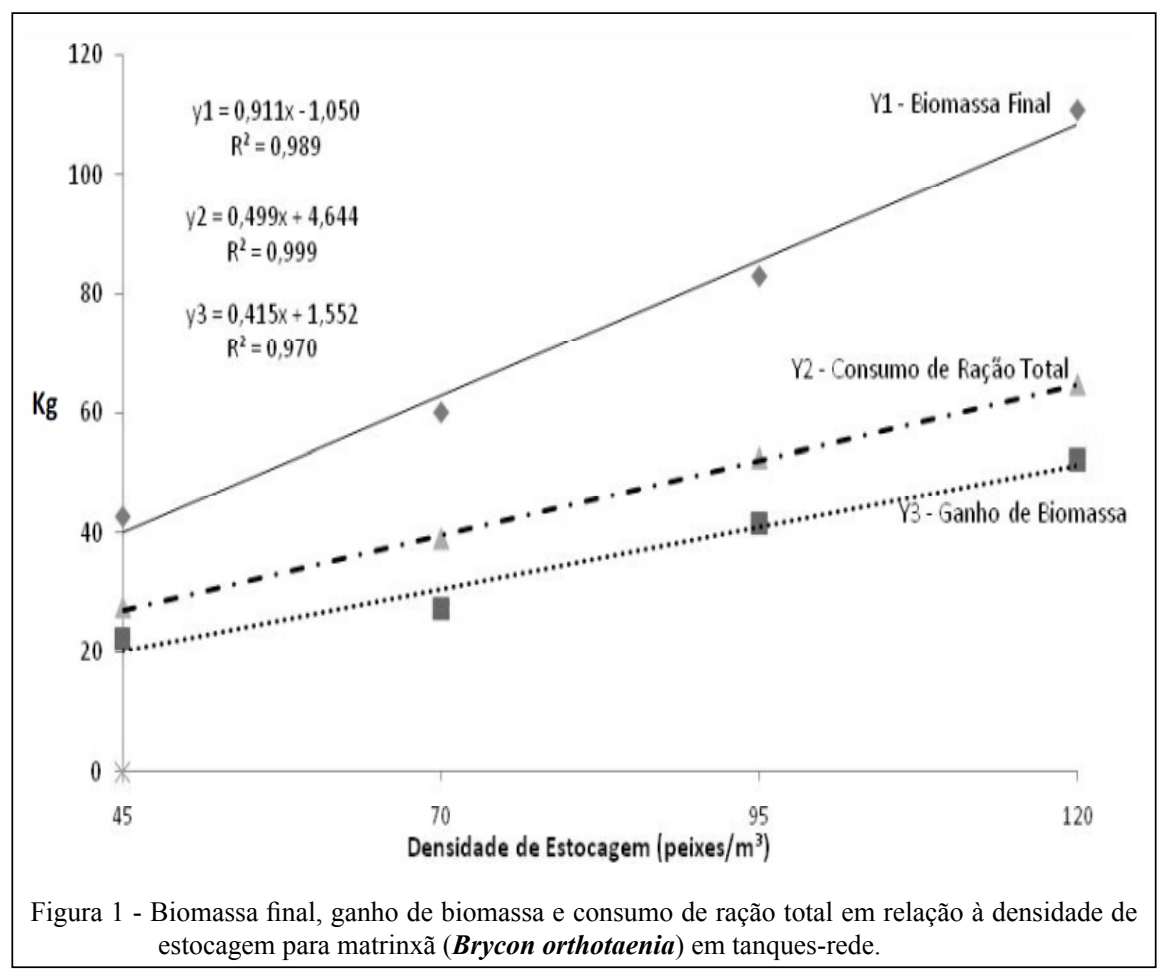

para taxa de crescimento específico, devido ao comportamento agressivo e formação de territórios com estabelecimento de hierarquias dominantes entre os peixes, o que ocasionou maior gasto metabólico, apetite e crescimento reduzido.

\section{CONCLUSÃO}

Nas condições em que o presente estudo foi realizado, pode-se concluir que a densidade de estocagem de 120 peixes $\mathrm{m}^{-3}$ foi a que proporcionou maior produtividade no cultivo de matrinxã de 115 a $240 \mathrm{~g}$.

\section{AGRADECIMENTOS}

Os autores deste trabalho agradecem ao Conselho Nacional de Desenvolvimento Científico e Tecnológico - CNPq, pelo financiamento desta pesquisa.

\section{COMITÊ DE ÉTICA E BIOSSEGURANÇA}

Este estudo foi aprovado pela Comissão de Ética no Uso de Animais n.049/11.

\section{REFERÊNCIAS}

BRANDÃO, F.R. et al. Densidade de estocagem de juvenis de tambaqui durante a recria em tanques-rede. Pesquisa Agropecuária Brasileira, v.39, n.4, p.357-362, 2004. Disponível em: <http:// dx.doi.org/10.1590/S0100-204X2004000400009>. Acesso em: 10 jan. 2012. doi: 10.1590/S0100-204X2004000400009.
BRANDÃO, F.R. et al. Densidade de estocagem de matrinxã (Brycon amazonicus) na recria em tanques-rede. Pesquisa Agropecuária Brasileira, v.40, n.3, p.299-303, 2005. Disponível em: <http://dx.doi. org/10.1590/S0100-204X2005000300014>. Acesso em: 8 dez. 2011. doi: 10.1590/S0100-204X2005000300014.

BRASIL. Resolução CONAMA n.357, de 17 de março de 2005. Brasília.

BRASIL. Ministério da Agricultura e Reforma Agrária. Normais climatológicas: 1961 - 1990. Brasília: MARA, 1992. 84p.

CARDOSO, E.L.; FERREIRA. R.M.A. Cultivo de peixes em tanques-rede: EPAMIG/IEF. In: Cultivo de peixes em tanques-rede: desafios e oportunidades para um desenvolvimento sustentável. Belo Horizonte: EPAMIG, 2005. p.9-22.

CARNEIRO, P.C.F. et al. Estudo de caso da criação comercial da tilápia vermelha em tanques-redes: avaliação econômica. Informações Econômicas, v.29, n.8, p.52-61, 1999.

CARVALHO, R.A.P.L.F. et al. Efeito da densidade de estocagem no desempenho do matrinxã, Brycon cephalus (Günther, 1869), cultivado em tanques-rede no período do inverno. Boletim Instituto de Pesca, v.24, n.esp, p.177-185, 1997.

FRASCA-SCORVO, C.M. et al. Efeito do manejo alimentar no desempenho da matrinxã Brycon amazonicus em tanques de cultivo. Acta Amazônica, v. 37, n. 4, p. 621-628, 2007. Disponível em: $<$ http://dx.doi.org/10.1590/S0044-59672007000400018>. Acesso em: 15 jan. 2012. doi: 10.1590/S0044-59672007000400018.

GOMES, L.C. et al. Efeito do volume do tanque-rede na produtividade de tambaqui (Colossoma macropomum) durante a recria. Acta Amazonica, v.34, n.1, p.111-113, 2004. Disponível em:

Ciência Rural, v.43, n.6, jun, 2013. 
$<$ http://dx.doi.org/10.1590/S0044-59672004000100014>. Acesso em: 13 jan. 2012. doi: 10.1590/S0044-59672004000100014.

IBGE (INSTITUTO BRASILEIRO DE GEOGRAFIA E ESTATÍSTICA). Anuário Estatístico do Brasil, v.59, p.1/1-8/29, 1999.

INOUE, L.A.K.A. et al. Óleo de cravo como anestésico para juvenis de matrinxã Brycon cephalus (Günther, 1869). Ciência Rural, v.33, n.5, p.943-947, 2003. Disponível em: <http://dx.doi. org/10.1590/S0103-84782003000500023>. Acesso em: 11 jan. 2012. doi: 10.1590/S0103-84782003000500023.

IUCN. IUCN Red List of Threatened Species. 2011. Version 2011.1. Disponível em: <www.iucnredlist.org>. Acesso em: 19 set. 2011 .

IZEL, A.C.U. et al. Avaliação de níveis protéicos para a nutrição de juvenis de matrinxã (Brycon cephalus). Acta Amazônica, v.34, n.2. p.179-184, 2004. Disponível em: <http://dx.doi.org/10.1590/ S0044-59672004000200005>. Acesso em: 10 jan. 2012. doi: 10.1590/S0044-59672004000200005.

LAGO, A.A. Densidades de estocagem de matrinxã Brycon orthotaenia na fase de recria em tanques-rede instalados em um braço do Reservatório de Três Marias. 2010. $57 \mathrm{f}$. Dissertação (Mestrado em Zootecnia) - Universidade Federal de Lavras, Lavras, MG.

MARQUES, N.R. et al. Influência da densidade de estocagem no cultivo de alevinos de matrinxã Brycon cephalus (Günther, 1869) em condições experimentais. Acta Scientiarum - Biological Sciences, v.26, n.1, p.55-59, 2004.

PAIVA, M.P. Grandes represas do Brasil. Brasília: Editerra, 1982. 304p.

PEDRAZANI, A.S. Reconhecimento da senciência e proposta de método alternativo de abate. 2007. 72f. Dissertação (Mestrado em Ciências Veterinárias) - Universidade Federal do Paraná, Curitiba, PR.

PEDREIRA, M.M. et al. Cultivo de matrinxã Brycon orthotaenia (Günther, 1864) em tanques-rede, em diferentes densidades de estocagem. Acta Scientiarum - Biological Sciences, Maringá, v.32, n.1, p.17-22, 2010.

PIAIA, R.; BALDISSEROTTO, B. Densidade de estocagem e crescimento de alevinos de jundiá Rhamdia quelen (QUOY e GAIMARD, 1824) fingerlings. Ciência Rural, v.30, n.3, p.509513, 2000. Disponível em: <http://dx.doi.org/10.1590/S0103-
84782000000300024>. Acesso em: 16 jan. 2012. doi: 10.1590/ S0103-84782000000300024.

SATO, Y. et al. Padrões reprodutivos de peixes da bacia do São Francisco. In: GODINHO, H.P.; GODINHO, A.L. (Org.). Águas, peixes e pescadores do São Francisco das Minas Gerais. Belo Horizonte: PUC Minas, 2003. 468p. p.229-274.

SATO, Y.; GODINHO, H.P. Peixes da bacia do rio São Francisco. In: LOWE-McCONNELL, R.H. Estudos ecológicos de comunidades de peixes tropicais. São Paulo: Edusp, 1999. 534p. p.401-413.

SOUZA, M.L.R. Efeito de sistemas de aeração e densidades de estocagem sobre o desempenho e características de carcaça da tilápia do Nilo (Oreochromis niloticus). 1996. 140f. Dissertação (Mestrado em Aquicultura) - Universidade Estadual Paulista, Jaboticabal, SP.

SURESH, A.V.; LIN, C.K. Effect of stocking density on water quality and production of red tilapia in a recirculated water system. Aquaculture Engineering, v.11, n.1, p.1-22, 1992. Disponível em: <http://dx.doi.org/10.1016/0144-8609(92)90017-R>. Acesso em: 16 jan. 2012. doi: 10.1016/0144-8609(92)90017-R.

TORTOLERO, S.A.R. et al. Efeito da densidade de estocagem no crescimento da matrinxã, Brycon amazonicus (Spix e Agassiz, 1829) em gaiolas de pequeno volume. Revista Brasileira de Engenharia de Pesca, v.5, n.1, p.81-92, 2010.

TURRA, E. M. et al. Densidade de estocagem do surubim Pseudoplatystoma sp. cultivado em tanque-rede. Revista Brasileira Saúde Produção Animal, v.10, n.1, p.177-187, 2009.

VALENCIO, N.F.L.S. et al. A precarização do trabalho no território das águas: limitações atuais ao exercício da pesca profissional no alto-médio São Francisco. In: GODINHO, H.P.; GODINHO, A.L. (Org.). Águas, peixes e pescadores do São Francisco das Minas Gerais. Belo Horizonte: PUC Minas, 2003. 468p. p.423-446.

VILELA, C; HAYASHI, C. Desenvolvimento de juvenis de lambari Astyanax bimaculatus (Linnaeus, 1758), sob diferentes densidades de estocagem em tanques-rede. Acta Scientiarum, v.23, n.2, p.491-496, 2001 .

WELCOMME, R.L. River fisheries. Roma: FAO Fish, 1985. p.1-330. (Tech. Pap. 262).

ZANIBONI FILHO, E. et al. Cultivo de peixes em tanques-rede e impactos ambientais. In: CARDOSO, E.L.; FERREIRA. R.M.A. Cultivo de peixes em tanques-rede: desafios e oportunidades para um desenvolvimento sustentável. Belo Horizonte: EPAMIG, 2005. p.57-80. 